\title{
INNOVATIVE CONCEPT OF COILING MACHINE INTEGRATED WITH ROLLING MILL TO REPLACE THE STIRRUP MAKING PRACTICES
}

\author{
T.A. Madankar ${ }^{1}$, M.M.Gupta ${ }^{2}$, J.P. Modak $^{3}$ \\ ${ }^{1}$ Research Scholar \& Assistant Professor, Department of Industrial Engg, Shri. Ramdeobaba College of Engineering \\ \& Management, Nagpur, India. Madankarta@Rknec.Edu \\ ${ }^{2}$ Professor, Department of Mechanical Engg., Shri. Ramdeobaba College of Engineering \& Management, Nagpur, \\ India.Guptamm@Rknec.Edu \\ ${ }^{3}$ Emeritus Professor \& Dean $(R \& D)$, Department of Mechanical Engg., Priyadarshani College of Engg, Nagpur, \\ India.Jpmodak@Gmail.Com
}

\begin{abstract}
:
Building Construction Involves Use Of Stirrups To Give Strength To Columns And Beams And Are Widely Used In Various Shapes In Steel Reinforcement. It Is Regular Practice To Make Stirrups On Construction Sites. Existing Engineering Standards Recommend Use Of Continuous Helical Coil For Better Strength Of Structure But It Is Having A Very Rudimentary Level Of Technology. Hence This Work Focuses On Developing A Coiling Machine As An Integrated System Of The Rolling Mill Where The Steel Bars Are Produced. The Integrated Coiling Machine Will Overcome Almost All Problems And Limitations Associated With Manual Stirrup Making And Even Of Semiautomatic And Full Automatic Stirrup Making Machines. This Paper Embarks On Integration Of Stirrup Making Activity With Rolling Mill So As To Take The Advantages Of Plastic Deformation Of Steel At Elevated Temperature, Imbibing The Metallurgical And Mechanical Properties And Eliminating Residual Stresses Compared To Todays Stirrup Making Practices.
\end{abstract}

Key Words: - Stirrup, Rolling Mill, Helical Coil, Coil

\section{INTRODUCTION}

Civil structure without reinforcement is beyond imagination. Concrete material is several times strong in compression but weak in tension. If a concrete block is subjected to shear stress, failure may occur by diagonal tension. To safeguard the concrete structure against such failure, reinforcement is required. This reinforcement is called shear reinforcement which is provided by the element called as stirrup or lateraltie. Stirrup is one of the indispensable elements of reinforced cement concrete used for avoiding sagging of horizontal beam and buckling of vertical column along with the longitudinal member of it.

According to need of shapes of column and beams various shapes of stirrups are used such as rectangular, square, circular, triangular, hexagonal, etc. made out of, $8 \mathrm{~mm}$, $10 \mathrm{~mm}, 12 \mathrm{~mm}$ either in plain mild steel or torr steel. Steel used for reinforcement is $\mathrm{Fe} 250, \mathrm{Fe} \mathrm{415,} \mathrm{Fe} 500$ or equivalent grade of steel. Existing engineering standards recommend use of continuous coil for better strength [1]. It out-ways reduction in strength because of discrete stirrups. The reinforcement structures using various shapes of stirrups are as shown in following figures.

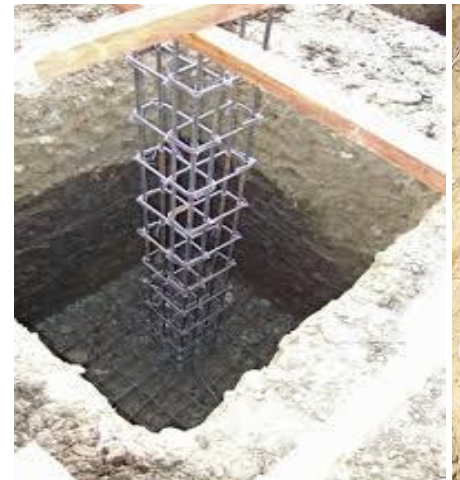

Fig.1.1RectangularStirrups

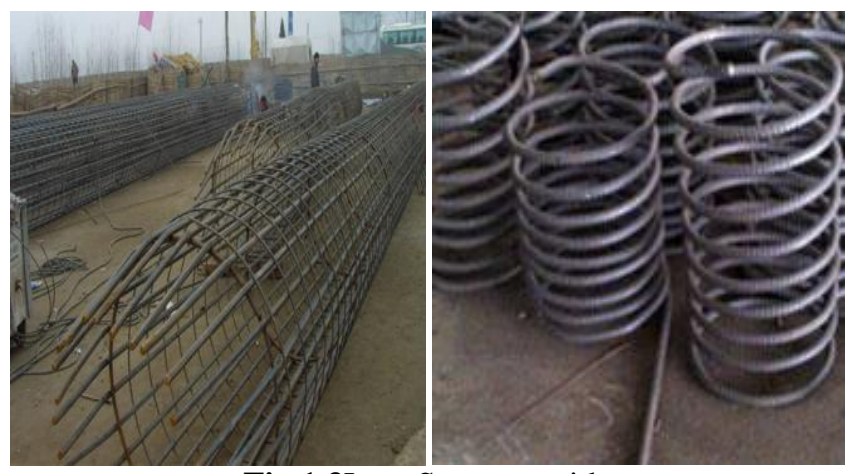

Fig.1.3LongStructurewith

Fig.1.4 Helical Coil Stirrup Circular Stirrups 


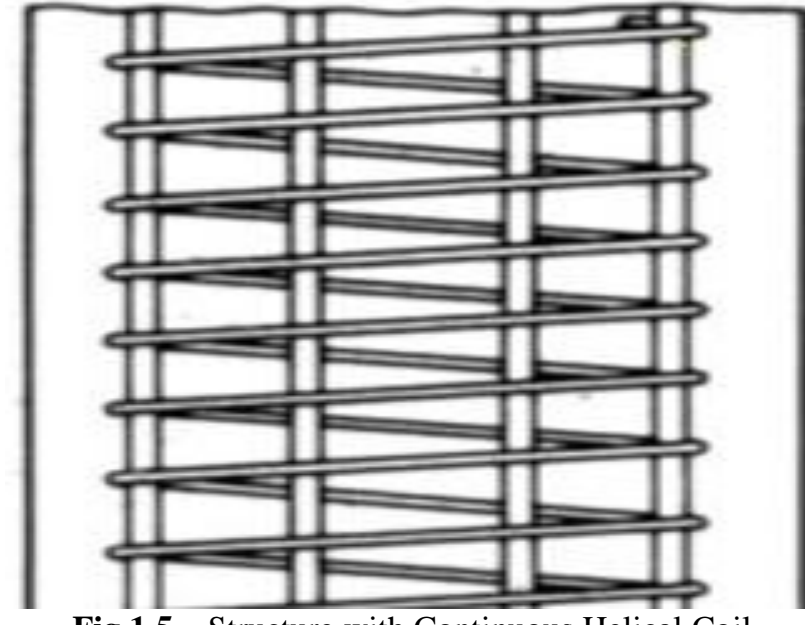

Fig.1.5 Structure with Continuous Helical Coil

Making a continuous coil on construction site experiences large difficulty. In the same way making it in factory involved loading and unloading of bars and additional transportation. Special feeding mechanism is needed to feed the bar in stirrup making mechanism which is also used for coiling the bar. Especially it is cold working process. Therefore it consumes more power[2].

Instead of taking the bar on construction site or in the stirrup making factory, the continuous coiling can be done at the outlet of last stand of rolling mill. The attempt is made to utilize the momentum gain by the bar due to rolling action of the rollers for feeding it in coiling mechanism. The entire process is carried out at elevated temperature. Thus heat reduces the yield point due to softening of metal thereby is an assurance of reduction in power requirement. This work will examine the possibility of integration

\section{PRESENT SCENARIO:-}

Now days many types of mechanical equipments are used in the construction processes. This mechanization allows an extensive gain in saving of time, high productivity, uniformity of product, eliminate or minimize human intensive process, reduce health hazards, minimize the wastage and reduce overall cost of product. However, considerable amount of work on the construction side is being done either by manual labor or semi- automated machine. Similarly stirrups are made manually. Semi automated or fully automated processes are also used for manufacturing the stirrups. These processes are carried out either on construction site or in the factory.

Various methods are used for making stirrups. The manual process of making stirrups is extensively used in civil construction. In this process of stirrup making, the specified length of M.S. round bar is cut as per required size of stirrup. The operator uses a wooden block as a platform for bending on which three nails are fixed, around which the bending takes place. The cut bar is passed horizontally between the nails up to the chalk mark and bent using a lever, about the nail through an required angle. After completing one bend the operator lifts and reposition the bar for the next bending. In this way the operator makes all the required bends for making one stirrup. Number of specified length of bars are cut from standard length of bar and last piece of it may be wastage of process. Rectangular stirrup making process is shown in Fig. 1.6.

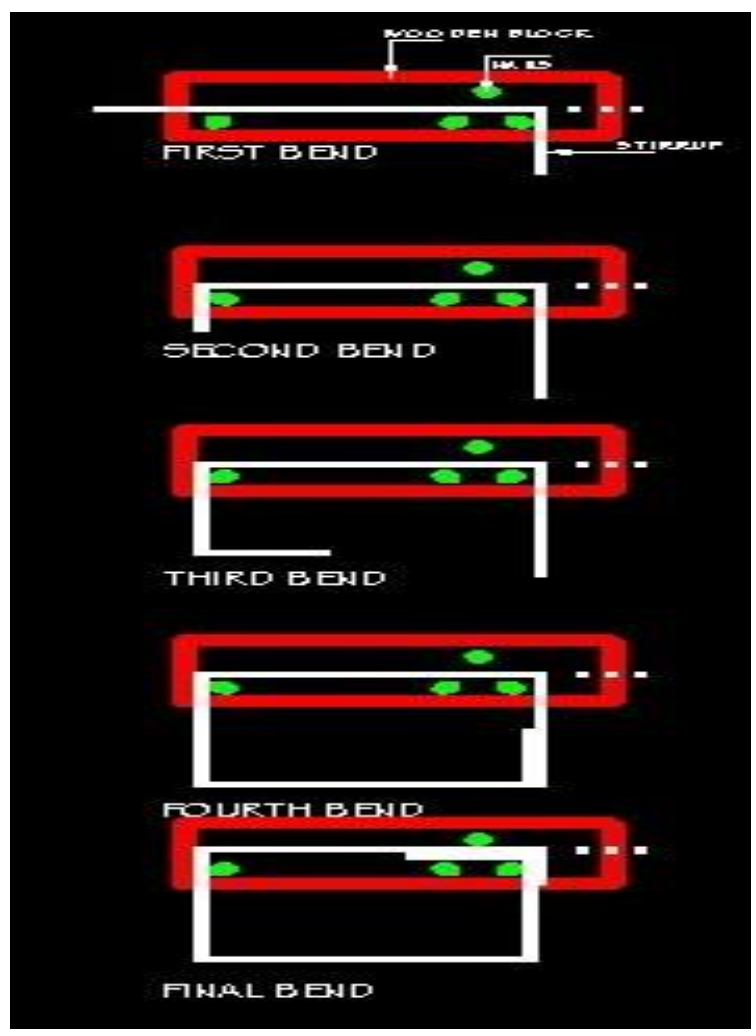

Fig. 1.6 Rectangular Stirrup Making Process (Conventional Process)

Semiautomatic machines for manufacturing of stirrups are readily available in the market. The few machine manufacturers are Consolidated Machine-Mumbai, RJS Steel Fabricators LLC-Atlanta-Georgia, etc. Semiautomatic processes are also designed \& developed by researchers. Vanalkar A.V.et.al., [2,3,4,5,6] designed \& developed semiautomatic motorized stirrup making machine. The required length of bar is cut and placed in feeding mechanism which further feed the bar to bending machine. With the help of cam and follower mechanism the number of require bends are given with specified angle to the bar for making the stirrup. Such a machine not only increases the production rate but also avoids the fatigue and muscular disorder of the operator.

Fully automated machines controlled by computer are the latest generation machine for making the stirrups and commonly available in the market. Orient AgencyMumbai(India), Alibaba group-China, Xuchang Fengyida Machinary Manufacturing Co. Ltd., China, etc are the leading manufacturer in this area[1]. The roll of bar is received from rolling mill. The complete roll is kept on stand to feed the bar in machine with the help of feeding mechanism. Massive power is required to feed the bar in stirrup making mechanism. Bending mechanism provides bends according to specified program prepared on computer. 
Any kind of shape of stirrup can be manufactured. The coil stirrup may also be produced. Basically it is cold working process. These machines are versatile in nature as various shapes of stirrups can be made. Macello Del. F. patented concept of automated stirrup making machine in 1979[7].

The rate of production in manual stirrup making process is 50 to 60 stirrups per hour \& 100 to 150 numbers per hour in semiautomatic machine depending on size of stirrups $[2,3,4]$. The production rate also goes up to the 400 numbers per hour, whereas fully automated machine produces more than 700 stirrups per hour [8].

\section{LIMITATIONS IN PRESENT METHODS OF STIRRUP MAKING:-}

Facility of manufacturing the coil stirrup is not available in manual or semi-automated processes. Ordinarily stirrup making is the cold working process. It is observed that hair cracks are developed on outer face of the bar during bending in cold working process which drastically reduces strength of stirrup. Reduction in size of bar and induction of residual stresses in the bar during bending further reduces the strength of material. Muscular disorder in operator, inaccuracy in work, limited production rate, non- uniformity in product, more time consumption, etc are the drawbacks in manual stirrup making process. Transportation of long bar, loading and unloading, shifting of bars at the stirrup making factory, again shifting of stirrups to the construction site, etc are the activities associated with present method of stirrup making.

\section{PROPOSED METHOD OF MANUFACTURING HELICAL COIL STIRRUPS:-}

In this paper, it is proposed that the bar coming out from the last stand of rolling mill can be turned into coil by integrating the coiling mechanism with rolling mill. The emphasize is given for making the circular continuous coil due to its simplicity in bending in the form of smooth curvature. The outer fiber of bar is in tension whereas inner fiber experiences the compression. To retain the given curvature to the bar, it is essential to take the fibers at plastic region of stress-strain curve. Elevated temperature of bar lowers the yield point and hardness of the metal. The analysis during bending is done for determining the strain energy induced in the various sizes of the bar. Thereby net power required for coiling is estimated. The amount of the forces required for taking the sufficient fibers to the plastic region is taken into account. The work encompass the synchronization of hot rolled bar to be received at coiling station. Due care should be taken while handling the bar because of high temperature and high speed of bar. Typically with hot condition, handling of the metal is hazardous. It is observed that the linear speed of the bar is between 3.5 to $4.0 \mathrm{~m} / \mathrm{s}$ along with the temperature around $600^{\circ} \mathrm{C}$, at the last stand of rolling mill. Considering all above mentioned issues the two basic types of mechanisms are proposed. One is drum coiling mechanism and another one is dowel mechanism as shown in the figure 4.1 and 4.2 respectively.

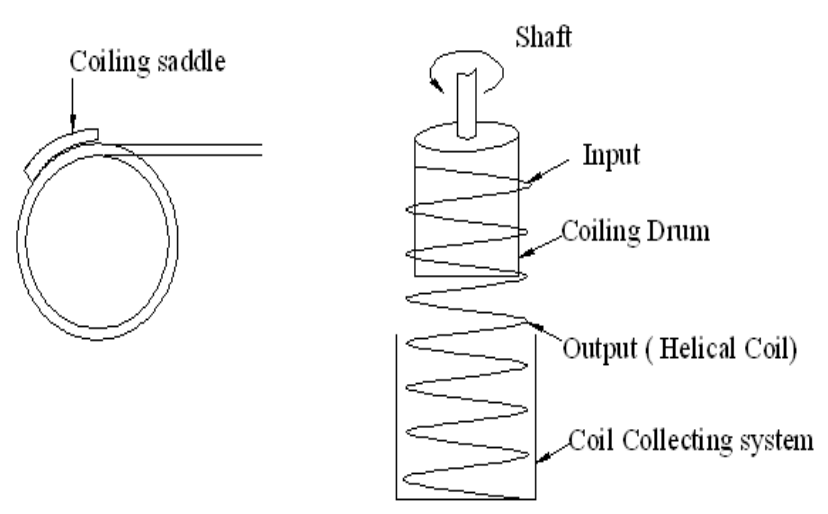

Fig 4.1 Drum Coiling Mechanism

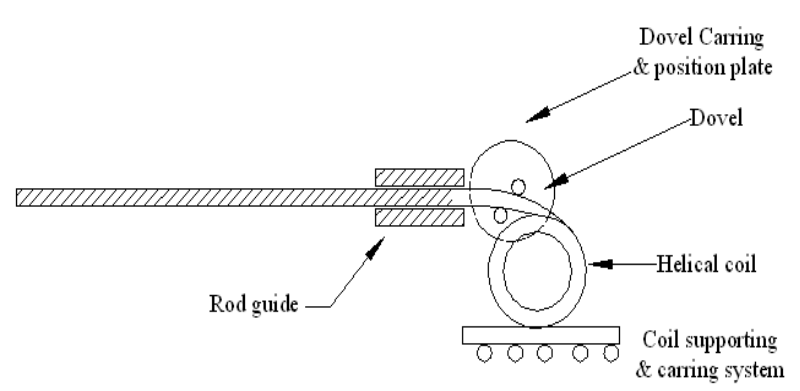

Fig 4.2 Dowel Mechanism

In drum coiling mechanism, a stationary saddle is used to turn the bar over the surface of rotary cylindrical drum. The arrangement is made to feed the bar in the gap between saddle and drum. The drum is mounted on the shaft from one end where as the end is kept open to remove the coil from mechanism. The spinning speed of drum is needed to synchronize with the linear speed of bar coming out from rolling mill. In dowel mechanism, the dowels are used to coil the bar by shifting the position of dowels with reference to rigid guide. The dowels are mounted on positioning plate. The bar coming out from rolling mill is fed to the stationary guide. Maintaining the straightness and providing the rigid support to the bar while bending by the dowels is the functional requirement of the guide. As soon as the bar reaches in the gap between the dowels, positioning plate provides the required position to the dowels for turning the straight bar into coil as shown in fig 4.2. Coil collector is kept below the coil for collecting it. Both the mechanisms have their merits and demerits. Drum coil mechanism has its own limitation of producing the different diameter of coils as per the need of civil construction. The series of limited varying diameters of drums is to be kept for the production of different diameters of coils. Changing the drum for every required change in diameter consumes the manpower and time. Maintenance and balancing is another issue with the drum mechanism. Dowel mechanism overcomes the limitations of first mechanism. The change in diameter of coil is obtained by only changing the relative position of dowels. Therefore set up time to change from one diameter to another is absolutely zero. All limitations of drum coil mechanisms are overcome by dowel mechanism. The mechanism to be deployed should support high mechanical working with securities and safety. 
This method produces coils in rolling mill, itself avoiding transport for stirrup making and according to need it can be cut to use as a individual stirrup or continuous helical coil. The entire coil making process is carried out at elevated temperature thereby helping in maintaining the metallurgical and mechanical properties of material[9]. In addition to this there is no wastage of bar due to continuous coiling process.

\section{ADVANTAGES OF PROPOSED METHOD}

The proposed method of manufacturing the coiling stirrup gives the following advantages:-

[1]. Hot condition of bar gives the advantages of bending at low power in plastic region.

[2]. No necessity of feeding mechanism.

[3]. The large amount of power can be saved for making the stirrups.

[4]. It avoids the hair cracks.

[5]. The coil passes through oblivious annealing, thereby relieving the residual stresses. Therefore coil stirrup has more strength than the stirrup produces in cold working process.

[6]. Due consideration can be given in sizing of the bar at the last stand of rolling mill for taking the care of reduction in size of bar in bending.

[7]. Different diameter of coil can be manufactured only by changing the position of bending pins.

[8]. Entire helical coil can be used as continuous stirrup.

[9]. As per the need, helical coil can be cut to make conventional stirrups.

[10]. Coil so produced has reasonably small length compare to original length of bar. Material handling becomes convenient and easier. Commercial bars are around 6 meters in length. The handling of long bars are cumbersome.

[11]. Use of such coils reduces onsite working. It saves labor and space.

[12]. Overall cost of stirrup could be reduced.

\section{LIMITATIONS OF PROPOSED METHOD:-}

Safety and synchronization with the rolling mill of speed of bar at elevated temperature is a major limitation that needs attention while designing coil making machine.

\section{CONCLUSION}

The integration of coiling mechanism with a rolling mill is a novel approach and would be a revolution in the field of stirrup making industry. It would provide a competitive edge in construction industry by eliminating wastage of time, material, money and energy involved ordinary stirrup making practices. The quality stirrups would lead to enhanced life of building structures as it would be produced in hot condition i.e. in plastic form of material, where mechanical and metallurgical properties are maintained to best values and overcoming the problem of residual stresses and surface cracks in ordinary stirrup making practices. Hence it can be concluded that there is a need to develop proposed coiling machine integrated with rolling mill.

\section{REFERENCES}

[1]. Indian Standard Code of Practice for Plain and Reinforced Concrete (4 ${ }^{\text {th }}$ Revision) - IS Code 456 2000, BIS, New Delhi,(2000).

[2]. Padole P.M.\& Vanalkar A.V., "Feeding System using Gearised DC Motor For Stirrup Making Machine", Proceeding $10^{\text {th }}$ National Conference on Machines and Mechanisms, Dec. 2001, IIT Kharagpur, India, pp. 255-260

[3]. Vanalkar A.V.\& Padole P.M.,“ Design, Development and Fabrication of Stirrup Making Machine', Proceedings of $9^{\text {th }}$ national Conference on Machines and mechanisms, December 1999, NACOMM 99, IIT, Pawai, Mumbai, India, pp. 341-352

[4]. Vanalkar A.V.\& Padole P.M.,“ Mechanism Synthesis for Stirrup Making Mechine. Proceeding, $4^{\text {th }}$ International Conference on Mechanical Engineering, ICME 2001, BUET, Dhaka, Bangladesh, pp271

[5]. Padole P.M.\& Vanalkar A.V.," Optimum Design of Mechanism for Stirrup Making Machine - A Computer Approach", $11^{\text {th }}$ National Conference on Machines and Mechanisms, IIT, Chennai

[6]. A.V, Vanalkar et. al.," Development of stirrup making machine", International Journal of mechanism and Machine Theory, (SLSMMT)2001,pp 37-39

[7]. United State Patent patented by Del. F. Marcello (1979) [4]. file:///H:/Stirrup Making machine.

[8]. Ikhar S., Vanalkar A. and Modak J.P., "Formulation of Field Data Based Model to Co-relate the Performance of Stirrup Rod Cutting Operation with Independent Variables of Activity", Industrial Engineering Journal, Vol. VI \& Issue No. 3,pp40-44, March 2013

[9]. Outinen J. \& Makelainen P, ' Mechanical Properties of Structural Steel at Elevated Temperatures and After Cooling down'. Second International Workshop Structure in Fire, Christchurch, March 2002. 